\title{
Microwave attenuation in forest fuel flames
}

\author{
K.M. Mphale ${ }^{a, *}$, P.V.C. Luhanga $^{a}$, M.L. Heron ${ }^{b}$ \\ a Physics Department, University of Botswana, P/Bag 0022, Gaborone, Botswana \\ ${ }^{\mathrm{b}}$ Marine Geophysical Laboratory, James Cook University, Townsville, QLD 4811, Australia
}

Received 18 July 2007; received in revised form 2 July 2008; accepted 4 July 2008

Available online 11 August 2008

\begin{abstract}
The flames of forest fuels form a weakly ionized gas. Assuming a Maxwellian velocity distribution of flame particle and collision frequencies much higher than plasma frequencies, the propagation of microwaves through forest fuel flames is predicted to have attenuation and phase shift. A controlled fire burner was constructed where various natural vegetation materials could be used as fuel. The burner was equipped with thermocouples and used as a cavity for microwaves with a laboratory quality network analyzer to measure phase and attenuation. The controlled fires had temperatures in the range of 500-1000 K and microwave attenuation of $1.0-4.5 \mathrm{~dB} \mathrm{~m}^{-1}$ was observed across the $0.5 \mathrm{~m}$ diameter cavity. Attenuations of this magnitude could affect active remote sensing systems signals at microwave frequencies in forest fire environments where flame depths of up to $50 \mathrm{~m}$ are possible. In the experiment, temperature was not the only controlling parameter for the ionisation; type of fuel burnt also influenced it. Inductively Coupled Plasma-Atomic Emission Spectroscopy (ICP-AES) analysis of the composition of the fuel confirmed that a higher content of alkali (with low ionization potential) lead to higher electron densities. Electron densities in the range of $0.32-3.21 \times 10^{16} \mathrm{~m}^{-3}$ and collision frequencies of $1.1-4.0 \times 10^{10} \mathrm{~s}^{-1}$ were observed for flames with temperature in the range of 730-1000 K.
\end{abstract}

(c) 2008 The Combustion Institute. Published by Elsevier Inc. All rights reserved.

Keywords: Forest fire; Active remote sensing systems; Flame conductivity; Weakly ionized plasma; Attenuation; Thermal ionisation

\section{Introduction}

Australia is subject to recurring catastrophic forest fires, which results in huge economical and social cost. The forest fires are attributable to frequent drought spells and fire-prone vegetation [1]. The recurrence predominates in the sclerophyll forests of Western Australia, southeastern Australia in summer, and grassland ecosystems of the northern parts of the

\footnotetext{
* Corresponding author.

E-mail address: mphalekm@mopipi.ub.bw (K.M. Mphale).
}

continent during austral winter [2]. In Western and southeastern Australia, summers are generally hot and dry with hot winds blowing from the desert interior to the regions, desiccating vegetation tinder-dry [3]. Under these dehydrating conditions, eucalyptus species such as Jarrah (Eucalyptus marginata) and Karri (Eucalyptus diversicolor) rapidly shed large quantities of litter, which accumulate on forest floors [3]. The eucalyptus litter is laden with highly flammable oil, making eucalyptus forest highly susceptible to very high intensity forest fires. In the event of the high intensity fires, the litter is thermally decomposed to give volatiles together with plant's omnipresent al- 
kali metal species into the reaction zone of the fire. The intense heat in the reaction zone is capable of thermally decomposing the alkali species, which ultimately ionise to give ions and electrons.

Electrons, through collision with neutral particles in the fire, transfer energy from incident microwave signals to the gaseous flame medium. The absorption of energy by electrons in the flame can significantly attenuate signals [4,5]. Microwave absorption in a flame is a factor of both the quantity of ionisable impurities and flame temperature [5]. Belcher and Sugden [4] observed that X-band microwave signals propagating in alkali halide seeded coal-gas/air flame at a temperature of $2200 \mathrm{~K}$ are attenuated by up to $1 \mathrm{~dB} \mathrm{~cm}^{-1}$. The absorption was observed to be very small when the flame was not seeded. Schneider and Hofmann [5] recorded microwave attenuation of $1.8 \mathrm{~dB} \mathrm{~cm}^{-1}$ in a potassium chloride seeded acetylene-air flame of thickness $0.8 \mathrm{~cm}$ at the temperature of $2480 \mathrm{~K}$.

Vegetation fires are essentially hydrocarbon flames seeded with alkali-based species [6]. High frequency radio waves could be significantly attenuated by very high intensity vegetation fires as simulated in Boan [7]. Mobile radio communication and remote sensing radar systems operate at frequencies in the range of UHF to X-band, and are therefore likely to be affected by the ionised fire environment. Land mobile radio communication systems at UHF are used by most Australian Rural Fire Brigades during forest fire suppression. As a safety precaution, reliable and high performance communication equipment that is not impaired by a weakly ionised fire environment is necessary for fire brigades. There are anecdotal reports of failure to maintain line-of-sight (LOS) communication in mobile radio communication systems at $\mathrm{HF}$ and UHF during forest fire suppression (e.g., Griffiths et al. [8] and Williams et al. [9]). This is a safety concern for fire fighters working on a head fire, who often use LOS radio communication to discuss with incident commander on the best tactics for suppressing the threat. It is therefore, important to carry out a scientific investigation on radio wave energy absorption in fire environment.

The present paper reports on microwave propagation measurements in a controlled fire in which natural vegetation litter is used as fuel. Flames in the experiment were far much cooler than those described in Belcher and Sugden [4]. However, their temperature was in the range of that of moderate intensity forest fires. The paper also estimates the line integrated average electron density and collision frequency for gases in the reaction zone of the fires, as they are important for numerical propagation prediction of microwaves in forest fires environments.

\section{Vegetation combustion}

\subsection{Forest fire emissions}

Forest fires are uncontrolled combustion of natural vegetation. Weather, type of fuel and other conditions in the vicinity of the fire contribute significantly to the type of emissions and flame intensity. Most of the plant's organic structure is made up of cellulose, which accounts for about $40 \%$ of its weight [10]. Hemicellulose, lignin, extractives and mineral matter make up the rest of the plant matter. Cellulose is often used as chemical representative of plant material because of its abundance in the latter; hence its empirical formula is used to describe the combustion of dry plant matter (e.g., Radojevic [11] and Nassbaumer [12]). Nassbaumer [12] has given a detailed description of combustion of plant matter that emphasizes the importance of availability of oxygen (ambient air). The availability of air in the flame ensures high combustion efficiency and therefore, high flame temperatures. Plant combustion is described to proceed as follows:

$$
\begin{aligned}
& \mathrm{CH}_{1.44} \mathrm{O}_{0.66}+1.03 \beta\left(\mathrm{O}_{2}+3.76 \mathrm{~N}_{2}\right) \\
& \Rightarrow \text { Intermediates }\left(\mathrm{C}_{n}, \mathrm{C}_{X} \mathrm{H}_{Y}, \mathrm{CO}_{2}, \mathrm{H}_{2}, \mathrm{CO}, \mathrm{Na}\right. \\
& \quad \mathrm{KCl}, \mathrm{K} \text {, etc. }) \\
& \Rightarrow \mathrm{CO}_{2}+0.72 \mathrm{H}_{2} \mathrm{O}+(\beta-1) \mathrm{O}_{2}+3.87 \beta \mathrm{N}_{2},
\end{aligned}
$$

where $\beta$ is excess air ratio. Excess air ratio compares the amount of locally available combustion air to the stoichiometric amount. $\beta$ is greater than unity for when local combustion air is in excess of the stoichiometric amount, otherwise is less than unity. Intermediate products, also termed pyrolysates are formed when a fuel undergoes thermal decomposition usually in an area of insufficient air (i.e., in a region where $\beta<1$ ). Some of the pyrolysates are volatile and readily combust when they mix with oxygen of the air in the presence of a spark to produce water $\left(\mathrm{H}_{2} \mathrm{O}\right)$ and carbon dioxide $\left(\mathrm{CO}_{2}\right)$ in an exothermic reaction. Potassium $(\mathrm{K})$ species and graphitic carbon $\left(\mathrm{C}_{n}\right)$ form a major fraction of the inorganic emissions into the combustion zone from the thermally decomposing plant structure.

\subsection{Flame ionisation}

Flame temperatures in the combustion zone of a wildfire could be as high as $1330^{\circ} \mathrm{C}$ [13]. The fierce temperature could thermally excite the flame species (FPS $(\mathrm{g}))$ and consequently ionise them to produce electrons on selective basis determined by temperature and ionization potential. Thermal ionisation of 
FPS(g) species (S(g)) e.g., K and Na occur by the following reaction equation:

$\mathrm{FPS}(\mathrm{g}) \Leftrightarrow \mathrm{FPS}^{+}(\mathrm{g})+\mathrm{e}^{-}$,

where $\operatorname{FPS}^{+}(\mathrm{g})$ and $\mathrm{e}^{-}$are singly ionised particles and electrons, respectively. As potassium and graphitic carbon $\left(\mathrm{C}_{n}\right)$ constitute a major fraction of ionisable inorganic emissions in the forest fire flame and have low ionisation potentials of 4.34 and $8.5 \mathrm{eV}$, respectively [14], they produce most of the ionisation in the flame.

Chemi-ionisation is another possible mechanism by which significant ionization may occur in forest fire flames [15]. In the process, dissociation reactions provide part of the energy required for ionization since they are exothermic and the rest of it comes from the flame. Excited methyl radical $\left(\mathrm{CH}^{*}\right)$ is a known contributor to chemi-ionization in the hydrocarbon flames $[16,17]$. The $\mathrm{CH}^{*}$ radical reacts with oxygen atoms in the flame to produce $\mathrm{CHO}^{+}$ [18], and electrons according to the following reaction equation:

$\mathrm{CH}^{*}+\mathrm{O} \Rightarrow \mathrm{CHO}^{+}+\mathrm{e}^{-}$.

\section{Microwave attenuation from S-parameter measurements}

\subsection{Microwave attenuation by a vegetation fire}

The presence of electrons in a vegetation fire creates slightly ionised plasma. In the weakly ionised plasma, particles collide with each other. Electronneutral particle collision is the dominant form of particle interaction. The reason for the insignificance of other forms of interactions, such as electron-ion, electron-electron, ion-neutral, etc., is that (a) compared to electrons, other particles are far much heavier and therefore less mobile and (b) electrons and ionised particles are less numerous than the neutrals; therefore, the interaction of electrons with ionised particles is infrequent. When fire is illuminated with microwaves, electrons are accelerated by the electric field of the incident waves. Assuming that interaction between electrons and neutrals is elastic, the neutrals gain little kinetic energy during collisions mainly because they are relatively massive. Electrons are scattered isotropically but the average velocity after collision is zero. In this way, energy is transferred from microwaves to the neutral gas causing signal attenuation. The signal attenuation can be mathematically extracted from experimentally determined microwave propagation constant for a vegetation fire.

\subsection{Propagation constant}

The propagation constant $(\gamma)$ of a dielectric medium such as the weakly ionised flame is given by the following relation [19]:

$\gamma=\alpha_{\mathrm{f}}+i \beta_{\mathrm{f}}$,

where $\alpha_{\mathrm{f}}$ and $\beta_{\mathrm{f}}$ are attenuation and phase coefficients. When X-band microwaves illuminate weaklyionised, highly-collisional atmospheric pressure flame plasma, $\alpha_{\mathrm{f}}$ and $\beta_{\mathrm{f}}$ are related to electron-neutral collision frequency $\left(\varphi_{\text {eff }}\right)$ and ionisation by the expressions:

$\alpha_{\mathrm{f}} \cong \frac{\varphi_{\mathrm{eff}}}{2 c}\left[\frac{\omega_{\mathrm{p}}^{2}}{\left(\omega^{2}+\varphi_{\mathrm{eff}}^{2}\right)}\right]$

and

$\beta_{\mathrm{f}} \cong \frac{\omega}{c}\left[1+\frac{\omega_{\mathrm{p}}^{4}}{8\left(\omega^{2}+\varphi_{\mathrm{eff}}^{2}\right)^{2}} \frac{\varphi_{\mathrm{eff}}^{2}}{\omega^{2}}\right]$,

where

$\omega_{\mathrm{p}}=\left(\frac{N q_{\mathrm{e}}^{2}}{M_{\mathrm{e}} \varepsilon_{0}}\right)^{1 / 2}$,

$\varepsilon_{0}, N, q_{\mathrm{e}}, M_{\mathrm{e}}$ are the plasma collision frequency, free space permittivity, electron density, charge and mass, respectively. $\omega$ and $c$ are propagation cyclic frequency and speed of light in vacuum, respectively. Inverting (5) gives

$\frac{1}{\alpha_{\mathrm{f}}}=\frac{\varsigma\left(\omega^{2}+\varphi_{\mathrm{eff}}^{2}\right)}{\varphi_{\mathrm{eff}}}$,

where $\varsigma=2 c / \omega_{\mathrm{p}}^{2}$. Equation (7) is used to analyse experimental data by plotting $1 / \alpha_{\mathrm{f}}$ versus $\omega^{2}$ in order to get the observed values of electron density and collision frequency.

The propagation constant $(\gamma)$ can be measured indirectly using a Vector Network Analyser (VNA). The VNA measures scattering parameters (S-parameters) from which $\gamma$ can be determined. S-parameters measured from a two-port VNA are elements of $2 \times 2$ matrices that relate the intensity of the outgoing to the incoming waves (see Seeger [20]). Seeger has illustrated how the S-parameters for a Device Under Test (DUT), which in this case is fire, are measured.

Propagation factor $(P)$ is the ratio of the transmitted microwave amplitude transmitted to the incident and is related to $\gamma$ through the relation:

$P=e^{-i \gamma d}$,

where $d$ is the length of the path traversed by the electromagnetic beam through the flame. 


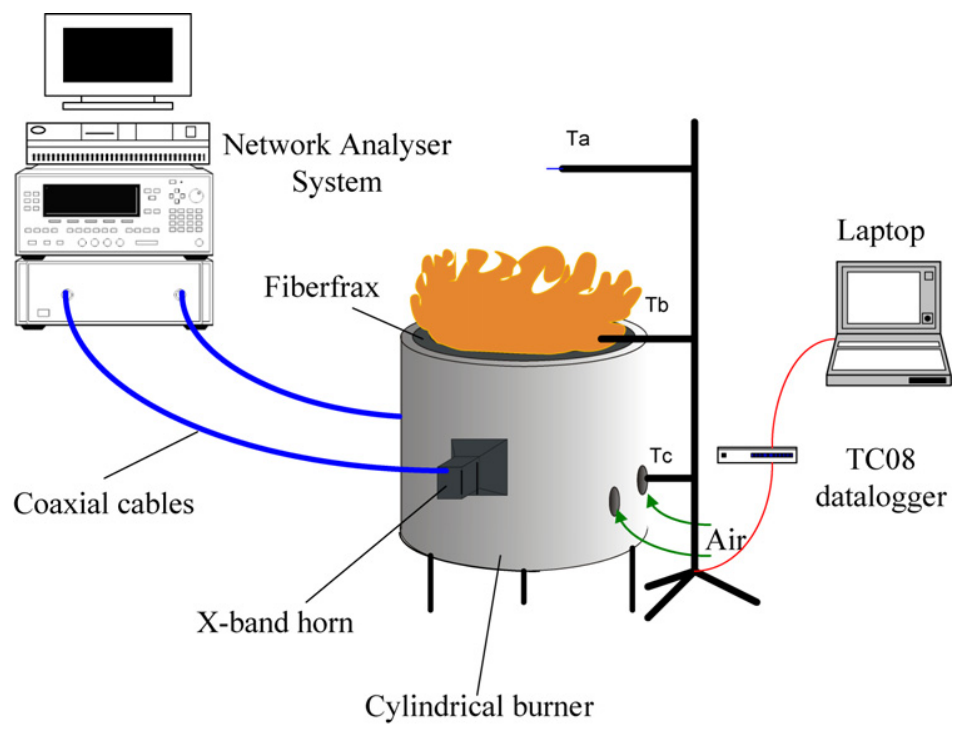

Fig. 1. Network analyzer set up for $S_{21}$ and $S_{11}$ parameter measurements.

The S-parameters determined from the VNA $\left(S_{11}\right.$ and $S_{21}$ ) are then used to determine $P$ from the relation [21]:

$P=\left[\frac{S_{11}^{2}+S_{21}^{2}-\Gamma}{1-\left(S_{11}+S_{21}\right) \Gamma}\right]$,

where $\Gamma$ is the reflection coefficient given by

$\Gamma=\Omega \pm \sqrt{\Omega^{2}-1}$,

where

$\Omega=\left(\frac{S_{11}^{2}-S_{21}^{2}+1}{2 S_{11}}\right)$.

The sign in (10) is chosen so that the magnitude of $\Gamma$ is less than 1 . With $P$ determined, $\gamma$ which is complex can be worked out from (8) as:

$\gamma=[\ln (1 / P)] / d$.

The real part of $\gamma$ gives the attenuation per unit propagation path length $\left(\alpha_{\mathrm{f}}\right)$.

\section{Experimental methods}

A fire was set in a hexagonally shaped wooden burner (see Fig. 1), which was fitted with thermocouples to measure fire temperature. Vegetation litter was used as fuel for the fire. X-band microwaves were then set to propagate at the fuel-fire interface, i.e., at the combustion zone of the fire.

\subsection{Natural forest fuel samples}

Samples used in the experiment consisted of litterfall from Eucalyptus platyphylla (poplar gum or eucalyptus), Panicum maximum (Guinea grass) and Pinus Caribea (pine) from the vegetation in and around the James Cook University campus in northern Queensland. Eucalyptus trees are endemic to most parts of Australia, while Guinea grass grows mainly in the tropics. Pines grow naturally in the eastern parts of Australia. The litter fall was collected and left to dry in the laboratory for about 10 days before being used for the experiment so as to improve combustion efficiency during the experiment.

\subsection{Forest fuel flame temperature measurement}

A thermocouple "tree" of about $1.25 \mathrm{~m}$ high was constructed from a steel pipe of diameter $0.025 \mathrm{~m}$. Side "arms" of length $0.4 \mathrm{~m}$ were wielded at every $0.25 \mathrm{~m}$ from the base of the tree to hold at least four thermocouples (Fig. 1, shown here with $3 \mathrm{arms})$. The thermocouples used were cut from a $100 \mathrm{~m}$ double braided fiberglass insulated chromelalumel $(24-\mathrm{G} / \mathrm{G})$ wire $50 \mu \mathrm{m}$ in diameter. The wire had a fibre glass shield which can withstand temperatures up to $450^{\circ} \mathrm{C}$. The type $\mathrm{K}$ thermocouple wires were electro-fused at one end to make perfect junctions. Beads were made small to minimise error in temperature readings due to heat transfer processes. The thermocouples were tested for accuracy and consistency in generated thermoelectric voltage using a hot air gun, thermometer and multimeter. They were then threaded in the steel pipe and then fixed to the 
tree arms by means of a muffler tape. The electrofused junctions were left protruded $1 \mathrm{~cm}$ beyond the arm length into the flame. The thermocouple tree was placed so that it measures temperature at the burner centreline. The thermocouples were wired to a PICO ${ }^{\circledR}$ Tech TC-O8 data logger and a laptop for on-line temperature measurement. In this experiment, temperatures of interest were those taken from the bottom thermocouple, thus the one wired at $0.25 \mathrm{~m}$ from ground surface and its position coincided with that of the fuel surface.

\subsection{Alkali and alkaline metal content in the forest fuel sample}

Vegetation samples were thoroughly washed with high purity deionized water and dried for $72 \mathrm{~h}$ in an oven set at $343 \mathrm{~K}$. The dried samples were then ground in a mill to a fine powder $(<0.5 \mathrm{~mm})$ to prepare them for acid digestion. The fine sample powders were then digested in a mixture of ultra-pure hydrogen peroxide $\left(\mathrm{H}_{2} \mathrm{O}_{2}\right)$ and super-pure nitric acid $\left(\mathrm{HNO}_{3}\right)$ in a microwave oven as in Asfaw et al. [22]. Standard solutions were prepared from the digests following Cai et al. [23]. A blank sample with the same amount of acid as the standard solutions was prepared with the same procedure for quality assurance. All samples including the blank were introduced into Inductively Coupled Plasma-Atomic Emission.

\subsection{S-parameter measurements}

The equipment used to measure the S-parameters for the fire consisted of a hexagonally shaped burner (Fig. 1) with an insulated wooden casing, a HewlettPackard 8577C network analyzer with X-band horns and a computer. The burner casing was hexagonally shape so as to allow easy conversion from one base cross section to another e.g. rectangular to circular without reconstructing the wooden casing. On the inside of the burner, a thick ( $8 \mathrm{~cm}$ thick) Fiberfrax ${ }^{\circledR}$ insulation was used to protect wood from the fire and heat. The material was lined to form a combustion area that was circular in base cross section. Two vent holes of $25 \mathrm{~mm}$ diameter were drilled on each of the sides, except the ones with horn inlets, to allow air to enter and mix with fuel during combustion. Two holes of horn dimensions were also cut out from the burner casing directly opposite each other and wooden supports were provided to secure the horns firmly to the wooden casing. The internal diameter of the burner lined with Fiberfrax ${ }^{\circledR}$ was set to $50 \mathrm{~cm}$. Adding to or slightly reducing the insulating material varied the propagation path length.

Two X-band transmit-receive horns were used in the experiment. They were connected to a network analyzer through the two-port S-parameter test set by coaxial cables. High quality mode transition adapters were used to make the connections between coaxial cables and the horns. The set up is shown in Fig. 1. The $8577 \mathrm{C}$ network analyzer set is designed to sweep from $50 \mathrm{MHz}$ to $40 \mathrm{GHz}$, logging in $601 \mathrm{~S}$-parameter data points in each and every sweep. The data are then uploaded to the computer. The analyzer takes $2 \mathrm{~s}$ to sample over one sweep, and then there is a latency of about $50 \mathrm{~s}$ before the next sweep can be initiated. The network analyzer was initially calibrated using the Transmit, Reflect and Line (TRL) method. Varadan et al. [24] give a full account of how the TRL calibration method is done. Several logging of S-parameters were carried out but only those in which flames covered the whole volume of the burner (by visual inspection) were chosen for analysis.

\section{Results and discussions}

\subsection{Thermocouple temperature correction}

There is a discrepancy between thermocouple measured fire temperatures and actual fire temperature. The error in temperature measurements, which could sometimes be more than $200 \mathrm{~K}$, is a result of heat transfer from the thermocouple bead to the surrounding gas (e.g., Dupuy et al. [25] and Daniels [26]). Convection and conduction heat transfer contribute but not significantly as radiation. Magnitude of the radiation error is mainly a function of thermocouple bead size and temperature of the radiating surfaces. Reducing the size of the thermocouple bead significantly reduces the measurement uncertainties. Martins et al. [27] observed that the error is small for thermocouples with beads less than $0.13 \mathrm{~mm}$.

Actual flame temperatures could be reconstructed from thermocouple readings using the energy balance equation. If it is assumed that flame gas is transparent to radiation, steady state energy balance for a thermocouple bead is given as [26]:

$\dot{q}_{\mathrm{cond}}+\dot{q}_{\mathrm{rad}}+\dot{q}_{\mathrm{conv}}=0$,

where $\dot{q}_{\text {cond }}, \dot{q}_{\text {rad }}$ and $\dot{q}_{\text {conv }}$ are rate of heat transfer by conduction, radiation and convection, respectively. The terms are positive or negative depending on whether the sensor is warmer or colder than its surroundings or its support. When it is assumed that conduction is symmetric about the burner centerline, Eq. (12) becomes

$$
\begin{gathered}
h A_{\mathrm{b}}\left[T_{\mathrm{g}}-T_{\mathrm{b}}\right]-\varepsilon_{\mathrm{th}} \sigma A_{\mathrm{b}}\left[T_{\mathrm{b}}^{4}-T_{\infty}^{4}\right] \\
-\left.2 k_{\mathrm{W}} A_{\mathrm{W}}\left(\frac{d T_{\mathrm{W}}}{d x}\right)\right|_{\mathrm{b}}=0,
\end{gathered}
$$




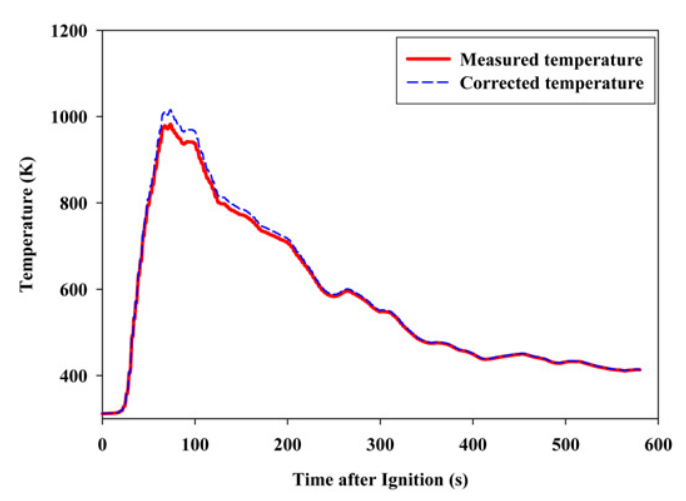

Fig. 2. A typical thermocouple measured temperature correction.

where $T_{\mathrm{g}}, T_{\mathrm{b}}$ and $T_{\mathrm{W}}$ are temperatures of the local flame gas, bead and thermocouple wire, respectively. $A_{\mathrm{W}}$ and $A_{\mathrm{b}}$ are surface areas of thermocouple wire and bead, respectively. Convective heat transfer coefficient, thermocouple emissivity and StefanBoltzmann constant are represented by $h, \varepsilon$ and $\sigma$, respectively. $K_{\mathrm{W}}$ represents thermal conductivity of the thermocouple wire. The last part of Eq. (13) is negligible for long thermocouple wires therefore reduces to:

$h A_{\mathrm{b}}\left[T_{\mathrm{g}}-T_{\mathrm{b}}\right]-\varepsilon_{\mathrm{th}} \sigma\left[T_{\mathrm{b}}^{4}-T_{\infty}^{4}\right]=0$.

Re-arranging Eq. (14) gives:

$\left[T_{\mathrm{g}}-T_{\mathrm{b}}\right]=\frac{\varepsilon_{\mathrm{th}} \sigma}{h}\left[T_{\mathrm{b}}^{4}-T_{\infty}^{4}\right]$.

Heat transfer coefficient,

$h=\frac{k N u}{d_{\mathrm{th}}}$,

where $k=\mu C_{\mathrm{p}} / P r, N u$ and $d_{\text {th }}$ are thermal diffusivity, Nusselt number and diameter of thermocouple bead. $C_{\mathrm{p}}, \mu$ and $P r$ are specific heat capacity, viscosity and Prandtl number, respectively.

Prandtl number for the flame gas is 0.71 . Nusselt number for forced convection for a cylinder is given by Dupuy et al. [25] as:

$N u=0.43+0.53 \operatorname{Re}^{0.5} \operatorname{Pr}^{0.31}$,

where

$R e=\frac{\rho_{\mathrm{g}} v_{\mathrm{g}} d_{\mathrm{th}}}{\mu} \quad$ and $\quad v_{\mathrm{g}}=\left[\frac{2 g I}{\rho_{0} C_{\mathrm{p}} T_{0}}\right]^{0.33}$.

Flame intensity $(I)$ is given by $q_{\mathrm{comb}} / \sqrt{A_{\mathrm{S}}}$ where also $q_{\text {comb }}$ and $A_{\mathrm{s}}$ are heat of combustion and flaming area, respectively. Dupuy et al. [25] give the error (Eq. (15)) as

$\left[T_{\mathrm{g}}-T_{\mathrm{b}}\right]=\frac{\sigma \varepsilon_{\mathrm{th}}\left(1-\varepsilon_{\mathrm{g}}\right) T_{\mathrm{g}}^{4}}{h+4 \sigma \varepsilon_{\mathrm{th}} T_{\mathrm{g}}^{3}}$

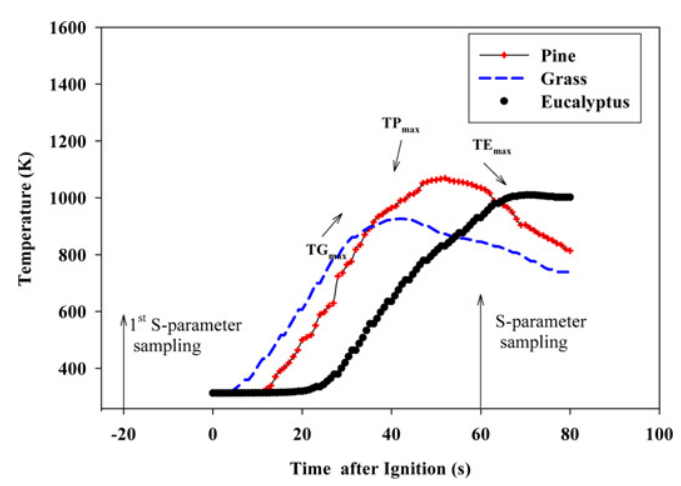

Fig. 3. Vegetation litter temperature (corrected) in the first $80 \mathrm{~s}$ after ignition.

and response time of the thermocouple sensor as

$\tau=\frac{\rho_{\mathrm{th}} C_{\mathrm{th}} d_{\mathrm{th}}}{4\left(h+4 \sigma \varepsilon_{\mathrm{th}} T_{\mathrm{g}}^{3}\right)}$.

The actual flame temperatures are determined by the use of iterative methods given in Welch et al. [28]. In this work, errors in flame temperatures were calculated following Welch et al. [28] and Dupuy et al. [25]. A typical thermocouple temperature correction is given in Fig. 2 for eucalyptus fire in the experiment. In Fig. 2, the blue dotted trace shows the actual flame temperature (corrected) while red graph is temperature variation as measured by a thermocouple.

\subsection{Fire temperatures}

Flames heights of about $75 \mathrm{~cm}$ were observed during the experiment. The flames from the combustion of pine needles and Guinea grass took 2-3 min to extinguish while those from eucalyptus leaves took about $6 \mathrm{~min}$. Pine needle and Guinea grass flames took about $5 \mathrm{~s}$ to fill the whole burner inner space. It took a little longer (approximately $10 \mathrm{~s}$ ) for eucalyptus leaves fire to fill the space. Radiation corrected $5 \mathrm{~s}$ moving average of temperatures measured during the first $140 \mathrm{~s}$ of fuel combustion at the fuel-flame interface by thermocouple Tc are shown in Figs. 3-4.

It is observed from Fig. 3 that in the first $5 \mathrm{~s}$ after ignition, the pine needle flame temperature rose rapidly to reach a maximum temperature $\left(\mathrm{TP}_{\max }\right)$ of $1069 \mathrm{~K}$ after $53 \mathrm{~s}$. The figure shows that Guinea grass temperature rose steadily to reach a maximum position $\left(\mathrm{TG}_{\max }\right)$ of $931 \mathrm{~K}$ after $44 \mathrm{~s}$. Eucalyptus flame temperature also rose steadily to reach a maximum value $\left(\mathrm{TE}_{\max }\right)$ of $1015 \mathrm{~K}$ after $74 \mathrm{~s}$. The first sets of $\mathrm{S}$-parameters were logged in after $60 \mathrm{~s}$ and that corresponded to Guinea grass, eucalyptus and pine leaves flame temperatures of 848,946 and $1035 \mathrm{~K}$, respectively. 


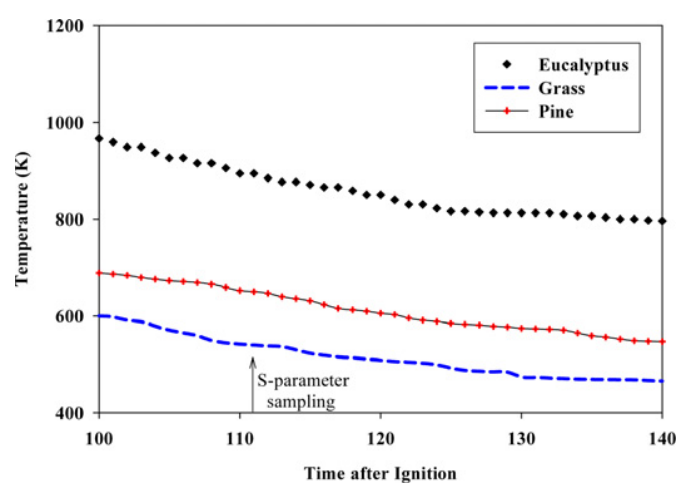

Fig. 4. Vegetation litter temperature (corrected) up to $140 \mathrm{~s}$ after ignition.

Table 1

Combustion behaviour of the samples in the hexagonal burner

\begin{tabular}{lllll}
\hline Fuel & $\begin{array}{l}\text { Bulk } \\
\text { density } \\
\left(\mathrm{kg} \mathrm{m}^{-3}\right)\end{array}$ & $\begin{array}{l}\text { Specific } \\
\text { gravity } \\
\left(\mathrm{kg} \mathrm{m}^{-3}\right)\end{array}$ & $\begin{array}{l}\text { Packing } \\
\text { ratio } \\
\left(\times 10^{-3}\right)\end{array}$ & $\begin{array}{l}\text { Max. emis- } \\
\text { sive power } \\
\left(\mathrm{kW} \mathrm{m}^{-2}\right)\end{array}$ \\
\hline Eucalyptus & 6.46 & 702 & 9.21 & 46.93 \\
Pine & 4.79 & 831 & 5.76 & 56.58 \\
Grass & 5.09 & 823 & 6.18 & 33.11 \\
\hline
\end{tabular}

After reaching the maximum value, the temperature for the pine leaves flame decreased rapidly to a value of $547 \mathrm{~K}$ after $140 \mathrm{~s}$ (see Fig. 4). However, Guinea grass and eucalyptus leaf flame temperatures decreased steadily to 465 and $796 \mathrm{~K}$, respectively, over the same period. After $111 \mathrm{~s}$, second sets of analysed S-parameters were logged in and corresponded to Guinea grass, pine needle and eucalyptus fire temperatures of 542, 652 and $894 \mathrm{~K}$, respectively.

The last sets of S-parameters were obtained when eucalyptus leaves were only fuel flaming and this was after $178 \mathrm{~s}$. The temperatures of the eucalyptus leaves flame, pine and Guinea grass ambers were 730, 489 and $438 \mathrm{~K}$, respectively, at this time.

During combustion, air more easily mixed with pine needles than other fuels as its packing ratio was $5.76 \times 10^{-3}$ and it is lowest ratio as read from Table 1. This implies that the volume of air around each pine fuel particle was higher than for other fuels. This rendered pine needle combustion to be more efficient than with other fuels hence the highest maximum flame temperature observed in the experiment. Guinea grass had packing ratio of $6.18 \times 10^{-3}$ (Table 1). It burned spontaneously during the experiment. Despite the rapid combustion, a much lower maximum temperature was recorded for this fuel. This could be explained by the fact that by nature grass is a light fuel with a lower heat of combustion compared to the other two fuels. Therefore, the heat produced

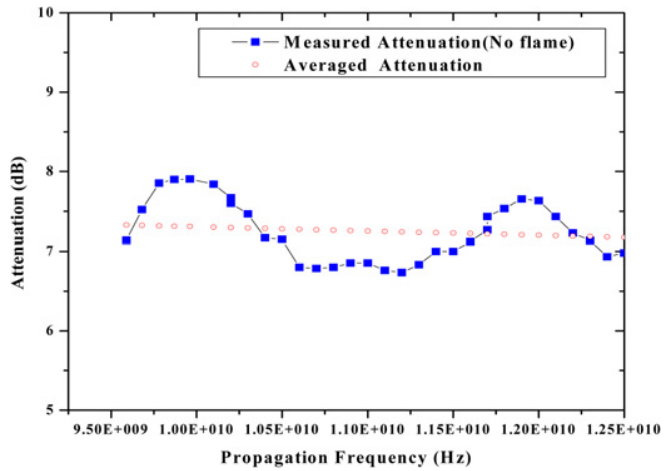

Fig. 5. Variation of attenuation with frequency for a burn cavity during without flame.

during combustion was not sufficient to raise its temperature beyond the maximum temperature of pine leaves. The burning of eucalyptus leaves was slowest as the leaves were closely packed and had the highest packing ratio of all the fuels with a value of $9.21 \times 10^{-3}$ (Table 1). Air could not mix well with the fuel as with the combustion of pine needles, therefore the maximum temperature observed for this fuel was lower than that observed in the combustion of pine leaves. The high packing ratio in eucalyptus leaves ensured low combustion efficiency and longer combustion duration.

\subsection{Microwave attenuation}

Propagation of microwave in the combustion zone of the leaves and grass flames has revealed that the zone is significantly ionized. Pine leaves burned fiercely and efficiently to produce the highest relative attenuation per meter of the flame during the experiment. The burner cavity with no flame and network analyzer system caused an average system's loss of about 7.1 dB per meter as shown in Fig. 5. Fluctuations in Figs. 6 and 7 are due to resonance in the chamber. At a frequency of $11.11 \mathrm{GHz}$, there are 18.5 wavelengths in the $50 \mathrm{~cm}$ chamber (in free space). This combined with a 180 degree per meter phase change on reflection gives a standing wave. As the frequency is increased, the next standing wave occurs at 19.5 wavelengths, which corresponds to $11.72 \mathrm{GHz}$. The frequency difference of 0.61 is characteristic of the fluctuations in the figures. The amplitude of the fluctuations is less than the amplitude variations due to attenuation. Fitting the solid lines shown in the figures has filtered the effects of resonance.

Attenuation measurements during flaming (Figs. 6 and 7) are relative to the system's loss. Relative attenuation observed after $60 \mathrm{~s}$ (see Fig. 6) shows that over the X-band frequency range of $9.8-12.5 \mathrm{GHz}$, the relative attenuation per meter of flame due to pine 


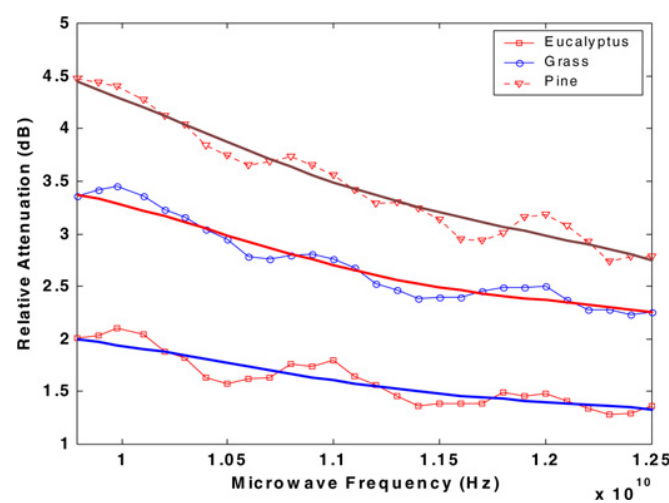

Fig. 6. Variation of attenuation with frequency during flaming of three vegetation litter after $60 \mathrm{~s}$.

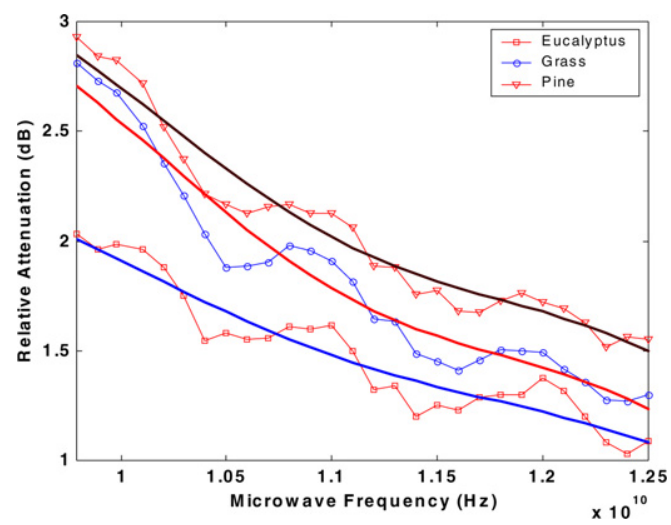

Fig. 7. Variation of attenuation with frequency during flaming of three vegetation litter after $111 \mathrm{~s}$.

needles was $4.45-2.73 \mathrm{~dB}$. Guinea grass and eucalyptus leaf flames produced attenuations of 3.36-2.27 dB and $2.00-1.32 \mathrm{~dB}$, respectively, over the same frequencies. From the results, it appears that temperature is not the only factor that affects attenuation. At $111 \mathrm{~s}$ (see Fig. 7), the loss due to eucalyptus leaves was lower than that due to Guinea grass even though the temperature of eucalyptus leaves flame was higher than of Guinea grass.

At $111 \mathrm{~s}$ (see Fig. 7), relative attenuation per meter of the flame due to pine needles decreased to 2.84$1.50 \mathrm{~dB}$ while that due to the eucalyptus and Guinea grass had fallen to $2.70-1.25 \mathrm{~dB}$ and $2.00-1.09 \mathrm{~dB}$, respectively, for the whole frequency range.

At $178 \mathrm{~s}$, Guinea grass and pine needles had stopped flaming. The surface of the fuels glowed red hot with some small naked flames at the sides. Eucalyptus leaves still burned with flames but there were parts which did not flame but glowed fiercely. Eucalyptus leaf flames attenuated the microwaves by about 0.96-2.22 dB per meter of flame whereas Guinea grass and pine needles weakened the power of the

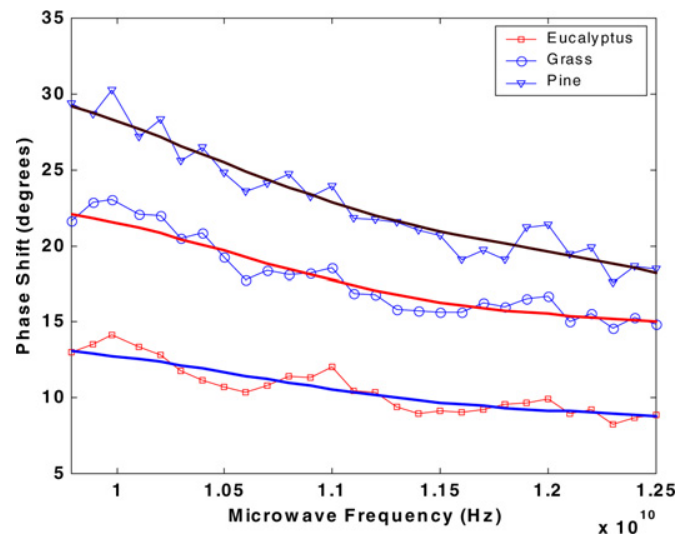

Fig. 8. Variation of phase shift with frequency during flaming of three vegetation litter after $60 \mathrm{~s}$.

microwaves by $2.28-1.36 \mathrm{~dB}$ and $2.20-1.09 \mathrm{~dB}$ per meter, respectively, at this frequency range.

\subsection{Measured phase shift}

The measured phase shifts due to the flames decreased with increasing frequency. Pine needle flame had a higher impact than grass and eucalyptus leaves flames. Generally, the flames imposed a phase shift less than 180 degrees per meter. After $60 \mathrm{~s}$, phase shift due to the pine needle flame decreased from 29.3 to 18.3 degrees per meter of flame over the X-band frequency range of $9.8-12.5 \mathrm{GHz}$ (see Fig. 8). A similar trend was also observed was observed for the two other flames. For eucalyptus leaves and Guinea grass the phase shift decreased from 13.1 to 8.8 and from 22.1 to 5.0 degrees per meter of flame, respectively.

After $111 \mathrm{~s}$, microwave phase shift continued to decrease with frequency. Phase shift measured for eucalyptus leaves flame decreases from 13.1 to 7.1 degree per meter over $9.75-12.5 \mathrm{GHz}$ frequency range (see Fig. 9). For Guinea grass and pine needles the phase shift decreased from 17.8 to 8.3 and from 18.8 to 10.0 degrees per meter, respectively.

After $178 \mathrm{~s}$, phase shift due to eucalyptus leaves flame decreases from 14.5 to 6.3 degrees per meter over the frequency range. Guinea grass and pine needles phase shift decreased from 14.9 to 9.1 and from 14.5 to 7.3 degrees per meter, respectively, over the frequency range.

From the measurements, microwave phase shift in the vegetation flames seems to be related to temperature and fuel type. The rate of decrease of phase shift with frequency for eucalyptus leaves flame was got steeper with time while that of grass and pine needles flames got steadier during the experiment. This could be explained by the amount of ionisation in the flames since phase shift is directly dependent on 


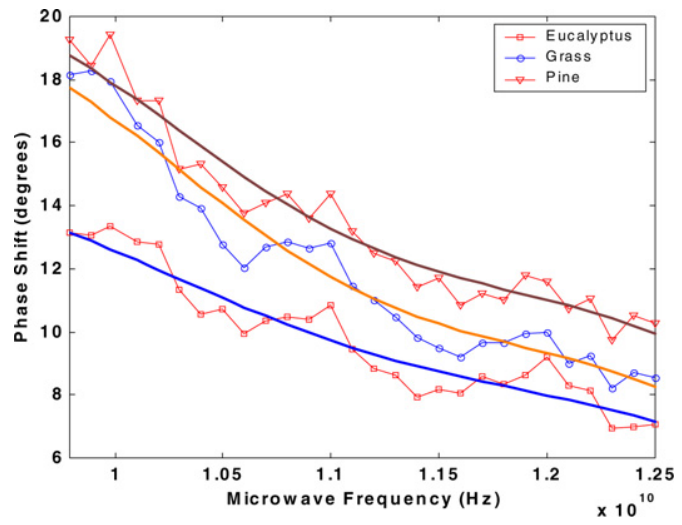

Fig. 9. Variation of phase shift with frequency during flaming of three vegetation litter after $111 \mathrm{~s}$.

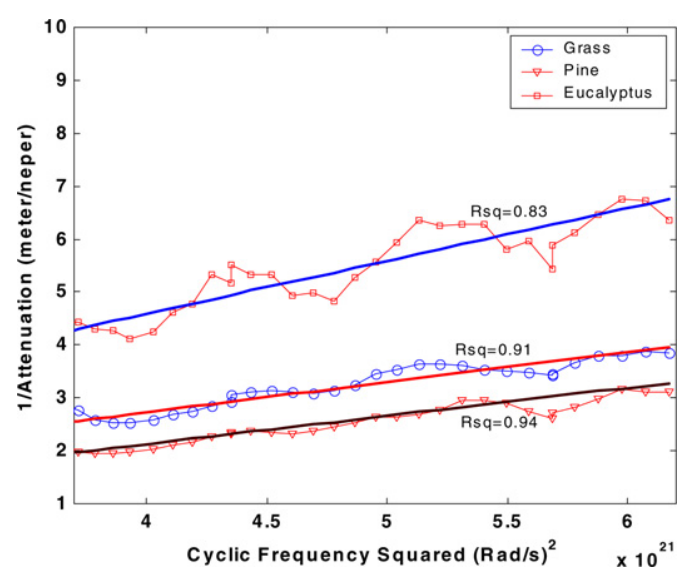

Fig. 10. Variation of 1 /attenuation with cyclic frequency squared during flaming of three vegetation litter after $60 \mathrm{~s}$.

electron density. It took longer time for the organic structure eucalyptus leaves to thermally disintegrate, a process that release the organically bound alkalis in to combustion zone, than for pine needles and grass.

\subsection{Electron density and collision frequency during flaming}

Electron density and collision frequency were calculated by plotting the inverse of attenuation $\left(1 / \alpha_{\mathrm{f}}\right)$ against cyclic frequency $\left(\omega^{2}\right)$. This gave a linear graph with $\left(\varsigma / \varphi_{\text {eff }}\right)$ as the gradient and $\varsigma \varphi_{\text {eff }}$ as the ordinate at zero abscissa (see Eq. (7)). At $60 \mathrm{~s}$ (see Fig. 10), the gradient of the graph for eucalyptus flame was observed to be $9.98 \times 10^{-22}$ and the ordinate was $5.98 \times 10^{-1}$. For the pine needles, the gradient of the plot was $5.31 \times 10^{-22}$ and the ordinate was noted to be $6.5 \times 10^{-2}$. The Guinea grass plot showed a gradient of $5.70 \times 10^{-22}$ and the ordinate was noted to be $4.48 \times 10^{-1}$. The gradient and ordinate values gave electron density and colli- sion frequency for the eucalyptus leaves, pine needles and Guinea grass to be $7.73 \times 10^{15} \mathrm{~m}^{-3}$ and $2.41 \times$ $10^{10} \mathrm{~s}^{-1} ; 3.21 \times 10^{16} \mathrm{~m}^{-3}$ and $1.11 \times 10^{10} \mathrm{~s}^{-1}$; and $1.18 \times 10^{16} \mathrm{~m}^{-3}$ and $2.80 \times 10^{10} \mathrm{~s}^{-1}$, respectively (Tables 3 and 4).

At $111 \mathrm{~s}$, the gradient and the ordinate for eucalyptus leaves are $1.19 \times 10^{-21}$ and $2.57 \times 10^{-1}$. Pine needles and Guinea grass gave $1.02 \times 10^{-21}$ and $-6.04 \times 10^{-1}$; and $1.50 \times 10^{-21}$ and $-2.34 \times 10^{-1}$ as their gradient and the ordinate, respectively. The gradients and ordinate gave calculated electron density and collision frequency as; $1.08 \times 10^{16} \mathrm{~m}^{-3}$ and $1.47 \times 10^{10} \mathrm{~s}^{-1} ; 7.62 \times 10^{15} \mathrm{~m}^{-3}$ and $2.44 \times$ $10^{10} \mathrm{~s}^{-1}$; and $5.50 \times 10^{15} \mathrm{~m}^{-3}$ and $1.47 \times 10^{10} \mathrm{~s}^{-1}$ for eucalyptus leaves, pine needles and Guinea grass, respectively (Tables 3 and 4). After $178 \mathrm{~s}$, the gradient and ordinate for eucalyptus leaf flame were $1.69 \times 10^{-21}$ and -2.09 , respectively. These gave the collision frequency and electron density as $3.52 \times$ $10^{10} \mathrm{~s}^{-1}$ and $3.18 \times 10^{15} \mathrm{~m}^{-3}$. The collision frequency values were observed to increase slightly during smoldering. This was due to the fact that neutrals moved into the space that was previously occupied by flame particles in order to balance the pressure to the atmospheric pressure.

Collision frequency as determined from the graphical method is inversely related to flame temperature. Thus, it increased with the decrease in fire temperature. After $60 \mathrm{~s}$, fire collision frequency was low for pine and Guinea grass fires. However, it increased as the flames got cooler (less then $800 \mathrm{~K}$ ) after $111 \mathrm{~s}$. A similar behaviour was observed for eucalyptus fire which was low near fire temperature maximum and higher after 60 and $178 \mathrm{~s}$.

Electron density in the fire increased with flame temperature, an inverse relationship to collision frequency. It was observed that ionization was low for eucalyptus flame at $60 \mathrm{~s}$ and higher after 111 and $178 \mathrm{~s}$. The electron density was high for pine and grass fires after $60 \mathrm{~s}$ and lower after $111 \mathrm{~s}$. Eucalyptus has a high heat of combustion than the other two fuels. Comparatively, a lot of heat was required to thermally decompose the eucalyptus leaves so that they could release organically bound alkalis than grass and pine needles.

The pine needle fire was the hottest and spread more quickly down the fuel bed than the other two flames (see Table 1). Large air spaces between the fuel particles ensured sufficient oxygen for efficient combustion, hence the highest maximum radiant heat flux observed. The effect of the flames on X-band microwaves does not seem to be directly related on the heat flux produced from combustion. Even though flames from Guinea grass have the least maximum radiant heat flux, its attenuation effect is higher than that of eucalyptus leaves throughout flaming combustion. 
Table 2

Alkali content in forest fuels used in the burner (ICP-AES method)

\begin{tabular}{llcl}
\hline Fuel & \multicolumn{3}{l}{ Alkali content $\left(\mathrm{mg} \mathrm{g}^{-1}\right)$} \\
\cline { 2 - 4 } & $\begin{array}{l}\text { Sodium } \\
(\mathrm{Na})\end{array}$ & $\begin{array}{l}\text { Potassium } \\
(\mathrm{K})\end{array}$ & $\begin{array}{l}\text { Calcium } \\
(\mathrm{Ca})\end{array}$ \\
\hline Eucalyptus & 0.188 & 6.62 & 7.67 \\
Grass & 0.132 & 12.9 & 4.64 \\
Pine & 0.092 & 3.50 & 1.65 \\
\hline
\end{tabular}

Table 3

Electron density in forest fuel flames

\begin{tabular}{llll}
\hline \multirow{2}{*}{$\begin{array}{l}\text { Time } \\
(\mathrm{s})\end{array}$} & \multicolumn{3}{l}{ Fuel flame electron density $\left(\times 10^{16}\right)$} \\
\cline { 2 - 4 } & Eucalyptus & Grass & Pine \\
\hline 60 & $0.77 \pm 0.03$ & $1.18 \pm 0.05$ & $3.21 \pm 0.08$ \\
111 & $1.08 \pm 0.05$ & $0.32 \pm 0.02$ & $0.76 \pm 0.04$ \\
178 & $1.47 \pm 0.06$ & Not flaming & Not flaming \\
\hline
\end{tabular}

Table 4

Collision frequency in forest fuel flames

\begin{tabular}{llll}
\hline \multirow{2}{*}{$\begin{array}{l}\text { Time } \\
(\mathrm{s})\end{array}$} & \multicolumn{3}{l}{ Fuel flame collision frequency } \\
\cline { 2 - 4 } & Eucalyptus & Grass & Pine \\
\hline 60 & $2.40 \pm 0.06$ & $2.80 \pm 0.07$ & $1.11 \pm 0.05$ \\
111 & $1.47 \pm 0.06$ & $3.95 \pm 0.09$ & $2.44 \pm 0.09$ \\
178 & $3.52 \pm 0.08$ & Not flaming & Not flaming \\
\hline
\end{tabular}

At these radiant heat fluxes, the contribution from thermal ionization of alkali metals may be significant. Alkalis have been observed to be emitted from the solid fuel matrix during char combustion [29]. The amount of alkalis emitted per unit time is a factor of both temperature and fuel particle size. Heat is required to thermally decompose the fuel so that the alkalis organically attached or in the transport vessels are freed first. Alkalis then thermally dissociate and consequently give electrons and positively charged ions.

The combined effect of both electrons in the flame and collision frequency absorbs energy from the microwaves. For example, pine needles in the experiment have low potassium content (see Table 2) but the combined effect of collision frequency and electron density was able to attenuate the microwaves much more than the other flames (see Tables 3 and 4). As the temperature decreased, however, the effect of collision frequency was reduced, and the combination with electron density was not strong enough to weaken the $\mathrm{X}$-band microwaves as much as the other two flames, for example, see Fig. 8.

Two cases can be used to compare values of attenuation and phase indices calculated from propagation theory and those determined from the experiment. The cases are flames of pine and eucalyptus leaves at
111 and $60 \mathrm{~s}$, respectively. At times, the momentum transfer collision frequency was $2.4 \times 10^{10} \mathrm{~s}^{-1}$ and electron densities of pine and eucalyptus leaves were $7.7 \times 10^{15} \mathrm{~m}^{-3}$ and $7.6 \times 10^{15} \mathrm{~m}^{-3}$, respectively. Using the values to back calculate attenuation and phase change indices gives attenuation index of 2.6$1.3 \mathrm{~dB} \mathrm{~m}^{-1}$ and phase change index of $15^{\circ}-10^{\circ} \mathrm{m}^{-1}$ in the frequency range of $8-12 \mathrm{GHz}$.

\subsection{Errors in electron density and collision frequency estimations}

As electron density and collision frequency were determined by a graphical method, gradient and ordinate values and their associated errors could be used to determine the errors for the parameters, e.g., in Baird [30]. Using this method, error in the electron density ( $\Delta N$ ed) and error in effective momentum transfer collision frequency $\left(\Delta \varphi_{\text {eff }}\right)$ are determined from the following expressions:

$\Delta N$ ed $=\frac{N \text { ed }}{2 \times \text { grad. } \times \text { ord }}\left\{\frac{\Delta \text { ord }}{\text { ord }}+\frac{\Delta \text { grad }}{\text { grad }}\right\}$

and

$\Delta \varphi_{\mathrm{eff}}=\frac{\varphi_{\mathrm{eff}}}{2 \times \text { grad. } \times \text { ord }}\left\{\frac{\Delta \text { ord }}{\text { ord }}+\frac{\Delta \mathrm{grad}}{\text { grad }}\right\}$,

where grad is the difference between the best and the worst fit slopes and ord is the difference in the ordinate intercepts of the best and the worst fits. They errors range from $3.2-4.8 \%$.

\subsection{Errors in attenuation and phase shift measurements}

In a similar method carried out by Trabelsi et al. [31] errors in attenuation and phase shift depend on values of electron density, collision frequency and their associated errors. The errors in attenuation and phase shift are calculated from the following relations:

$$
\Delta A=A\left\{\frac{\Delta N \text { ed }}{N \text { ed }}+\frac{\Delta d}{d}+\frac{\Delta \varphi_{\mathrm{eff}}}{\varphi_{\mathrm{eff}}}+\frac{2 \Delta \varphi_{\mathrm{eff}} \varphi_{\mathrm{eff}}}{\left(\omega^{2}+\varphi_{\mathrm{eff}}^{2}\right)}\right\}
$$

and

$$
\begin{aligned}
\Delta \Phi= & \Phi\left\{\frac{2 \Delta N \text { ed }}{N \text { ed }}+\frac{\Delta d}{d}+\frac{2 \Delta \varphi_{\text {eff }}}{\varphi_{\text {eff }}}\right. \\
& \left.+\frac{4 \Delta \varphi_{\text {eff }} \varphi_{\text {eff }}}{\left(\omega^{2}+\varphi_{\text {eff }}^{2}\right)}\right\} .
\end{aligned}
$$

They are calculated to range from 0.2 to $0.6 \mathrm{~dB}$ and from 0.2 to 1.3 degrees for attenuation and phase change, respectively. 


\section{Conclusions}

The electron density of forest fuel flames with radiant heat up to about $57 \mathrm{~kW} \mathrm{~m}^{-2}$ was calculated to range from 0.32 to $3.21 \times 10^{16} \mathrm{~m}^{-3}$. The electron densities determined in the experiment were lower than those produced from non-vegetation fuel flames at temperatures which are around $2000 \mathrm{~K}$. The amount of ionisation in the vegetation fires was a factor of fuel, combustion behaviour as well as flame temperature. We can be sure, however, that when forest fire temperatures get up to $1600 \mathrm{~K}$ (e.g., in Viegas [32]; Chandler et al. [33]) the electron densities will be higher for the same fuel type.

The collision frequency of the vegetation fires was in the ranges $1.1-4.0 \times 10^{10} \mathrm{~s}^{-1}$. The range is lower than electron-neutral collision frequency for flames in Belcher and Sugden [4], which was up to $8.8 \times 10^{10} \mathrm{~s}^{-1}$. Collision frequency is directly related to the electron, neutral gas densities and inversely related to flame temperature. For example, at ambient air temperature (approx. $300 \mathrm{~K}$ ), electronneutral collision frequency is about $2.3 \times 10^{12} \mathrm{~s}^{-1}$ [34] which is far higher than that of the flames at $2000 \mathrm{~K}$.

Attenuation in forest fuel flames is, however, related in a complex way to both electron density and collision frequency, which are related to both the alkali content and flame temperature. From the experiment, X-band microwaves suffered a relative attenuation in the range of $1.0-4.5 \mathrm{~dB} \mathrm{~m}^{-1}$ when propagating in a line-of-sight mode through flame of radiant heat up to $57 \mathrm{~kW} \mathrm{~m}^{-2}$. A phase shift of 29.3-6.3 degrees per meter was imposed on the microwaves.

The theory of electromagnetic wave propagation in weakly ionised plasma given in Koretzky et al. [35] and Akhtar et al. [34] predicts attenuation index in the range of $35.7-33.6 \mathrm{~dB} \mathrm{~m}^{-1}$ for the HF-UHF frequency band when mean values of the measured collision frequency and electron density are used. This implies that a UHF signal caused to propagate along the fire-fuel interface of a very intense ionised fire may be strongly attenuated.

\section{Acknowledgment}

We would like gratefully to acknowledge the Department of Electrical Engineering of JCU for providing the equipment for S-parameter measurement. The work is supported by the Staff Development Office of the University of Botswana. It is partly supported by Emergency Management Australia under project no. $60 / 2001$.

\section{References}

[1] N.G. Collect, Aust. Forestry 63 (1999) 1-7.

[2] D. Williams, G. Cook, in: R. Dyer, P. Jacklyn, I. Partridge, J. Russell-Smith, R.J. Williams (Eds.), Savanna Burning: Understanding and Using Fire in Northern Australia, Tropical Savanna, CRC, Darwin, 2002.

[3] R.J. Underwood, P.E. Christensen, Forest Fire Management in Western Australia, Government Printing Office, Perth, 1981.

[4] H. Belcher, T.M. Sugden, Proc. R. Soc. London A 201 (1067) (1950) 480-488.

[5] J. Schneider, F.W. Hofmann, Phys. Rev. 6 (2) (1959) 244-249.

[6] K.M. Mphale, M.L. Heron, J. Atmos. Sol.-Terr. Phys. 69 (2007) 471-484.

[7] J. Boan, Radio communication in fire environments, in: Proc. Wars2006 Conference, Leura, NSW, Australia, 2006.

[8] B. Griffiths, D. Booth, The effect of fire and smoke on VHF radio communication. CFA Investigative Report COMM-REP-038-1, Victoria, 2001.

[9] D.W. Williams, J.S. Adams, J.J. Batten, G.F. Whitty, G.T. Richardson, Operation Euroka: An Australian Mass Fire Experiment, Report 386, Defense Standards Laboratory, Maribyrnor, 1970.

[10] L.A. Brown, D.C. Dayton, J.W. Daily, Energy Fuels 15 (2001) 1286-1294.

[11] M. Radojevic, Pure Appl. Geophys. 12 (2003) 157187.

[12] T. Nussbaumer, Energy Fuels 17 (2003) 1510-1521.

[13] B.N. Butler, J. Cohen, D.J. Latham, R.D. Schuette, P. Sopko, K.S. Shannon, J. Jimenet, L.S. Bradhaw, Can. J. Forest Res. 34 (2004) 1577-1587.

[14] K.E. Shuler, J. Weber, J. Chem. Phys. 22 (3) (1954) 491-502.

[15] D. Latham, Atmos. Res. 51 (1999) 267-278.

[16] A. Sorokin, X. Vancassel, P. Mirabel, Atmos. Chem. Phys. 2 (2002) 2045-2074.

[17] A.G. Gaydon, H.G. Wolfhard, Flames: Their Structure, Radiation and Temperature, Chapman and Hall, London, 1979.

[18] C.J. Butler, A.N. Hayhurst, J. Chem. Soc. Faraday Trans. 98 (1998) 2729-2734.

[19] R.F. Whitmer, Phys. Rev. 104 (1956) 572-575.

[20] J.A. Seeger, Microwave Theory, Components and Devices, Prentice-Hall, New Jersey, 1986.

[21] A.H. Boughriet, C. Legrand, A. Chapoton, IEEE Trans. Microwave Theory Techn. 45 (1) (1997) 52-56.

[22] A. Asfaw, G. Wibetoe, Microchim. Acta 152 (2005) 61-68.

[23] Y. Cai, J. Su, L.Q. Ma, Environ. Pollut. 129 (2004) 6978.

[24] V.V. Varadan, K.A. Jose, V.K. Varadan, IEEE Trans. Microwave Theory Techn. 48 (2000) 388-394.

[25] J.L. Dupuy, J. Marechal, D. Morvan, Combust. Flame 135 (2003) 65-76.

[26] G.E. Daniels, J. Appl. Meteor. 7 (1968) 1026-1035.

[27] C.A. Martins, A.P. Pimenta, J.A. Carvalho, M.A. Ferreira, A.A. Caldeira-Pires, J. Braz. Soc. Mech. Sci. Eng. 27 (2005) 110-118. 
[28] S. Welch, A. Jowsey, S. Deeny, A. Morgan, J.L. Torero, J. Fire Safety 42 (2007) 548-567.

[29] J. Knudsen, P. Jensen, L. Weigang, F. Frandsen, K. Dam-Johan, Energy Fuel 18 (2004) 1385-1399.

[30] D.C. Baird, Experimentation: An Introduction to Measurement Theory and Experimental Design, PrenticeHall, New Jersey, 1988.

[31] S. Trabelsi, A.W. Kraszewski, S.O. Nelson, Meas. Sci. Technol. 9 (1998) 1548-1556.
[32] D.X. Viegas, Ann. Medit. Burns Club 16 (3) (1993) 17.

[33] C. Chandler, P. Cheney, P. Thomas, L. Trauband, D. Williams, Fire in Forestry, vol. I, Wiley, New York, 1983.

[34] K. Akhtar, E.J. Scharer, S.M. Tysk, E. Kho, Rev. Sci. Instrum. 74 (2) (2003) 996-1001.

[35] E. Koretzky, S.P. Kuo, Phys. Plasmas 5 (10) (1998) 3774-3780. 